\title{
iTRAQ-proteomics and bioinformatics analyses of mammary tissue from cows with clinical mastitis due to natural infection with Staphylococci aureus
}

\author{
Jinming Huang ${ }^{1 *}$, Guojing Luo ${ }^{1,2}$, Zijing Zhang ${ }^{1,2}$, Xiuge Wang ${ }^{1}$, Zhihua Ju', Chao Qi', Yan Zhang ${ }^{1}$, \\ Changfa Wang ${ }^{1}$, Rongling Li ${ }^{1}$, Jianbin $\mathrm{Li}^{1}$, Weijun Yin ${ }^{1}$, Yinxue $\mathrm{Xu}^{2}$, Sonia J Moisás, ${ }^{3,5}$, Juan J Loor ${ }^{3,4,5}$ \\ and Jifeng Zhong ${ }^{1 *}$
}

\begin{abstract}
Background: Proteomics and bioinformatics may help us better understand the biological adaptations occurring during bovine mastitis. This systems approach also could help identify biomarkers for monitoring clinical and subclinical mastitis. The aim of the present study was to use isobaric tags for relative and absolute quantification (iTRAQ) to screen potential proteins associated with mastitis at late infectious stage.

Results: Healthy and mastitic cows' mammary gland tissues were analyzed using iTRAQ combined with two-dimensional liquid chromatography-tandem mass spectrometry (2D-LC-MS/MS). Bioinformatics analyses of differentially expressed proteins were performed by means of Gene Ontology, metabolic pathways, transcriptional regulation networks using Blast2GO software, the Dynamic Impact Approach and Ingenuity Pathway Analysis. At a false discovery rate of 5\%, a total of 768 proteins were identified from 6,499 peptides, which were matched with 15,879 spectra. Compared with healthy mammary gland tissue, 36 proteins were significantly up-regulated $(>1.5$-fold) while 19 were significantly down-regulated $(<0.67$-fold) in response to mastitis due to natural infections with Staphylococci aureus. Up-regulation of collagen, type I, alpha 1 (COL1A1) and inter-alpha (Globulin) inhibitor H4 (ITIH4) in the mastitis-infected tissue was confirmed by Western blotting and Immunohistochemistry.
\end{abstract}

Conclusion: This paper is the first to show the protein expression in the late response to a mastitic pathogen, thus, revealing mechanisms associated with host tissue damage. The bioinformatics analyses highlighted the effects of mastitis on proteins such as collagen, fibrinogen, fibronectin, casein alpha and heparan sulfate proteoglycan 2. Our findings provide additional clues for further studies of candidate genes for mastitis susceptibility. The up-regulated expression of COLIA1 and ITIH4 in the mastitic mammary gland may be associated with tissue damage and repair during late stages of infection.

Keywords: iTRAQ, Proteomics, COL1A1, ITIH4, Dairy cow, Mastitis

\section{Background}

Mastitis, an inflammation of the mammary gland, remains the most prevalent disease and the largest economic loss in dairy cattle. The economic impact of mastitis on the U.S dairy industry in 1976 was estimated at $\$ 1.294$ billion and increased up to $\$ 2$ billion in the year of 2009 [1]. A large number of microorganisms, most of which are

\footnotetext{
* Correspondence: huangjinm@sina.com; zhongjifeng@tom.com 'Dairy Cattle Research Center, Shandong Academy of Agricultural Sciences, No.159 North of Industry Road, Jinan, Shandong 250131, China Full list of author information is available at the end of the article
}

bacteria, have been reported to cause bovine mastitis. Worldwide, however, the most common udder pathogens isolated from the clinical cases are Staphylococci aureus (S. aureus), Streptococcus dysgalactiae and Escherichia coli. The $S$. aureus is considered as a contagious mastitiscausing pathogen and remains an important mastitis pathogen in most countries [2]. The frequency of mastitis in the dairy cow population could potentially be decreased by breeding for cows with better ability to resist udder disease. Therefore, identifying specific genes involved in the susceptibility or resistance to mastitis could lead 
to new approaches for mastitis control through genetic selection [3].

Mastitis involves a complex set of interactions between an invading pathogen and immune systems of the host. Proteomics and the associated bioinformatics are considered as complimentary tools for the study the dynamic interactions between the immune system and pathogens [4]. Most proteomic studies on mastitis conducted to date have been performed using two-dimensional electrophoresis (2-DE) and liquid chromatography (LC) coupled with tandem mass spectrometry (MS) methods [5-8] and using milk, serum or somatic cells. For instance, differential expression analysis of the whey from both mastitic and non-mastitic milk revealed a series of proteins including acute phase proteins (APP), lactotransferrin and immunoglobulins that present a marked alternation during infection $[6,7]$.

Several studies have reported proteomics profiles in milk and serum of cows infected with different pathogens $[9,10]$. For instance, a total of 2971 milk proteins were identified and more than 300 milk proteins associated with host defense were identified in S. aureus infected and normal milk using the isobaric tag for relative and absolute quantification (iTRAQ) method [10]. Differentially expressed milk proteins at 2 and 14 days post-intramammary infection with different $S$. aureus strains have also been identified by $2 \mathrm{DE}$ [9]. Forty-seven peptide biomarkers of milk for the diagnosis of mastitis were discovered using capillary electrophoresis and mass spectroscopy [11].

The transcriptional response of the mammary gland to mastitis infected different pathogens has been reported in several microarray studies $[12,13]$, while information at the proteome level in mammary gland tissue is still limited particularly in animals with natural infections. Persistence of pathogen infections through late stages can worsen damage of the mammary gland and result in milk lost, or leave necrotic tissue and important injures [14]. Therefore, the investigation of changes in the protein expression upon the onset, progression and late onset of mastitis is crucial for providing a full picture of the events triggered by this disease. The exact quantification of differentially expressed proteins has proven difficult with gel-based approaches. Nevertheless, to date, there are no proteomic studies aimed at investigating the susceptibility to $S$. aureus-associated mastitis in dairy cows.

Here we present an exploration of the mastitis-induced changes in the proteome of mammary gland tissue using the iTRAQ system. This approach allows the simultaneous identification and quantitative comparison of peptides by measuring peak intensities of reporter ions in tandem mass spectrometry (MS/MS) spectra [15]. Differentially expressed proteins were used for bioinformatics analyses via the Gene Ontology (GO), Dynamic Impact Approach (DIA) [16] and the Ingenuity Pathway Analysis (IPA).

\section{Results}

Protein spectrum and GO analysis of mammary gland tissue of dairy cows

In the present study, iTRAQ technology in combination with LC-ESI-MS/MS was applied to investigate differentially expressed proteins in the healthy and mastitis-infected mammary glands of dairy cows. A total of 768 proteins were identified from 6499 peptides according to the standard of protein identification (Additional file 1). Of which, $35.42 \%$ proteins were identified with one peptide and $45.31 \%$ proteins with 3 to 177 peptides. COL1A1, collagen alpha-1(I) chain possesses the most of peptides. There are 177 peptides covering the $52.4 \%$ protein sequence with above $95 \%$ confidence. Several proteins like lactoferrin, MYH11, alpha-S1-casein, COL3A1, serum albumin, COL6A3 and COL1A2 were identified with over 50 peptides. Figure 1 shows the relative expression of two proteins (COL1A1 and ITIH4) in the healthy and mastitisinfected mammary gland tissues which was calculated as a ratio by comparing the intensity of the iTRAQ114 and TRAQ-117 after normalization.

Expressed proteins in mammary gland tissues of cows were classified by the DAVID online program (http://david.abcc.ncifcrf.gov/). These proteins were clustered into 178 clusters including cytoskeletal protein binding, signal peptides, etc. Gene functional annotation analysis indicated that thirty proteins such as, CD14, serum amyloid 3, casein alpha-S2, cathelicidin 2, cathelicidin 6, cathelicidin antimicrobial peptide, complement component 3 (C3), complement component 6 (C6), complement factor $B$ were involved in defense, immune and inflammatory reactions (Table 1). Six hundred genes participated in 32 pathways like ECM-receptor interaction (17 genes), complement and coagulation cascades (16 genes), and focal adhesion (30 genes) KEGG pathways (Additional file 2: Table S1).

\section{Identification and pathway analysis of the differential proteins between the healthy and mastitic cows' mammary gland tissues}

Basing on the standard of the differentially expressed proteins, 36 proteins were significantly differentially up-regulated ( $>1.5$-fold) while 19 proteins were significantly down-regulated $(<0.67$-fold $)$ in mastitis-infected cow group's proteins labeled ITRAQ-114 when compared with that of the healthy group's proteins labeled ITRAQ -117 (Table 2).

In term of GO database, the differentially expressed proteins were divided into $\mathrm{CC}, \mathrm{MF}$ and $\mathrm{BP}$ categories. The top $5 \mathrm{GO}$ terms for $\mathrm{CC}$ with the minimal $\mathrm{p}$ values were extracellular region, extracellular region part, extracellular space, extracellular matrix and extracellular matrix part (Additional file 3: Figure S1). The top 5 GO terms for MF were growth factor binding, cell surface binding, 


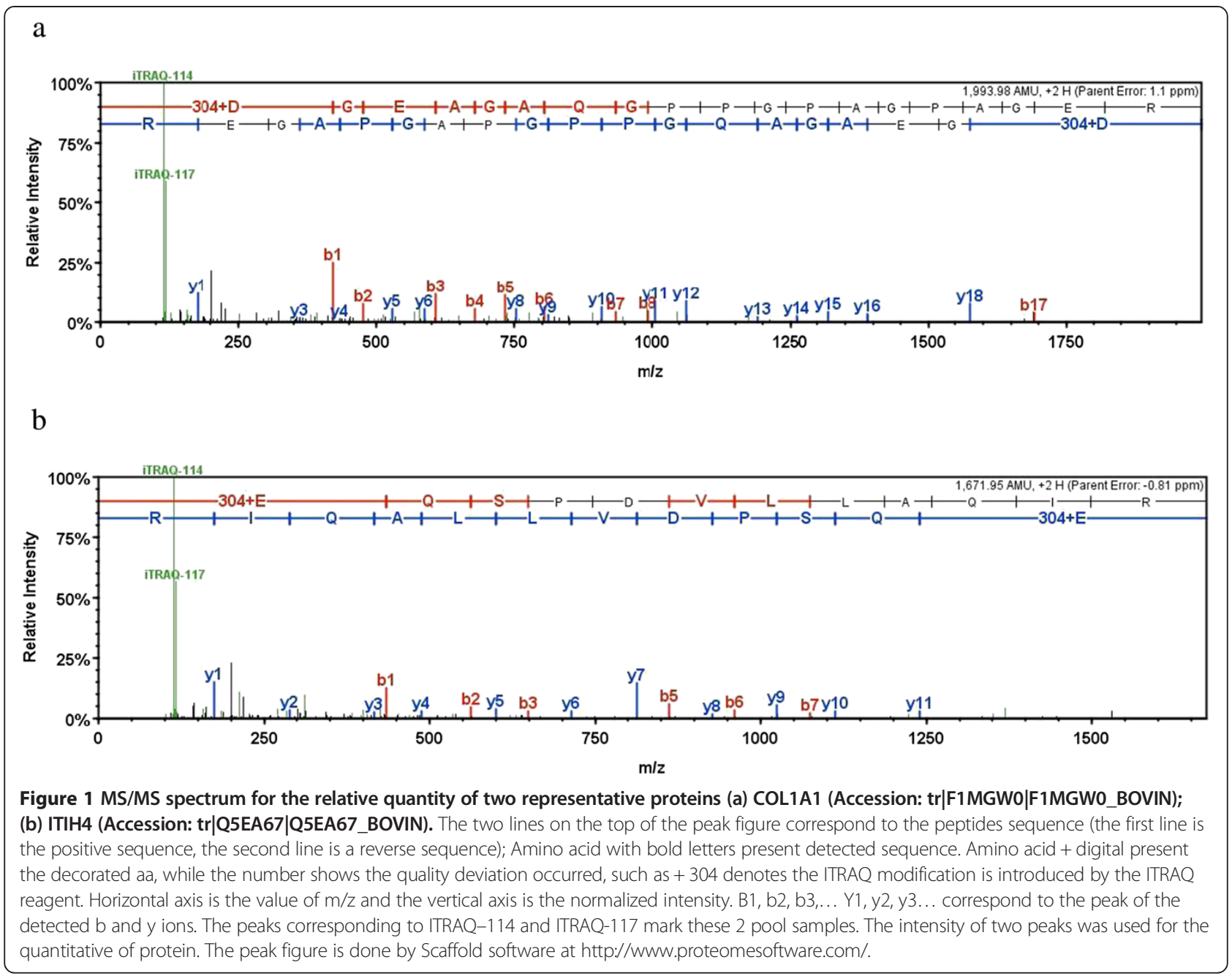

metal ion binding, motor activity and cation binding (Additional file 4: Figure S2). The top $12 \mathrm{GO}$ terms with a p-value $<0.01$ for MF were response to stress, response to stimulus, skeletal system development, response to inorganic substance, gas transport, peptide cross-linking, skin development, protein heterooligomerization, extracellular structure organization, response to steroid hormone stimulus, response to chemical stimulus and defense response (Additional file 5: Figure S3; Additional file 2: Table S2). For example, 10 proteins [alpha-S2-casein (CSN1S2), C-reactive protein (CRP), neutrophil gelatinaseassociated lipocalin (LCN2), thrombospondin-1 (THBS1), protein S100-A9 (S100A9), ENSBTAG00000047345, inter-alpha (Globulin) inhibitor H4 (ITIH4), protein S100-A12 (S100A12), protein S100-A8 (S100A8) and alpha-2-macroglobulin (A2M)] participated in the defense, immune and inflammatory responses (Additional file 2: Table S2). Another important protein was C3 with a p-value 0.06, involved also in the immune response (Table 1). Of 10 proteins, the expression of ITIH4 protein was increased by 4.55 -fold in the mastitis group when compared with the control group. ITIH4 protein was enriched in the membrane, cell, intracellular and intracellular part terms for CC (Additional file 3: Figure S1); it was also enriched in the nonpeptidase/peptidase/enzyme inhibitor/regulator activity terms for MF (Additional file 4: Figure S2); it is related with the response to stress/stimulus, defense response, acute or inflammatory response, amine/ carbohydrate/macromolecule/nitrogen compound metabolic processes terms for BP (Additional file 5: Figure S3). Moreover, according to the BP classification, the differential protein COL1A1 with the most of peptides were involved in $91 \mathrm{GO}$ terms, such as response to stimulus, extracellular structure organization, cellular component assembly, etc. (Additional file 2: Table S2; Additional file 5: Figure S3). COL1A1 enriched in the $12 \mathrm{GO}$ terms for CC, for example, extracellular region part, fibrillar collagen and intracellular part (Additional file 3: Figure S1). Basing on the MF classification, COL1A1 were also related with 4 GO terms including growth factor binding, structural molecule activity, proteins binding and binding (Additional file 4: Figure S2). 
Table 1 Proteins involved in the defense, immune and inflammatory reactions by DAVID analysis

\begin{tabular}{|c|c|c|c|c|c|}
\hline Accession & Protein names (full) & $\begin{array}{c}\text { Official gene } \\
\text { name }\end{array}$ & $\begin{array}{c}\text { Peptides } \\
\text { (95\%) }\end{array}$ & $\begin{array}{c}\text { Fold-change } \\
(114: 117) \\
\end{array}$ & $\begin{array}{l}P \text { value } \\
114: 117 \\
\end{array}$ \\
\hline $\operatorname{tr|Q06AV9~}$ & Monocyte differentiation antigen CD14 & CD14 & 2 & 1.20 & 0.77 \\
\hline $\operatorname{tr} \mid F 1 M Q F 6$ & Apoptosis-associated speck-like protein containing a CARD & PYCARD & 1 & & \\
\hline sp|P79105 & Protein S100-A12 & $\mathrm{S} 100 \mathrm{~A} 12$ & 6 & 11.11 & 0.00 \\
\hline sp|Q0VCA5 & SAM domain and HD domain-containing protein 1 & SAMHD1 & 2 & 0.85 & 0.71 \\
\hline $\operatorname{tr|F5CC79}$ & Beta-1,4-galactosyltransferase I & B4GALT1 & 2 & 0.89 & 0.22 \\
\hline $\operatorname{tr|BOJYN6}$ & Alpha-2-HS-glycoprotein & AHSG & 3 & 0.93 & 0.49 \\
\hline sp|P81644 & Apolipoprotein A-\| & APOA2 & 1 & 0.74 & 0.47 \\
\hline $\operatorname{tr|F1N3Q7}$ & Apolipoprotein A-IV & APOA4 & 5 & 0.24 & 0.01 \\
\hline sp|P02663 & Alpha-S2-casein & CSN1S2 & 25 & 0.19 & 0.00 \\
\hline tr|B9TUB8 & Cathelicidin 2 & CATHL2 BAC5 & 2 & 1.06 & 1.00 \\
\hline $\operatorname{tr|B9UKM3~}$ & Cathelicidin 6 & CATHL6 & 4 & 1.41 & 0.26 \\
\hline sp|P19661 & Cathelicidin-3 & CATHL3 BAC7 & 2 & 1.09 & 1.00 \\
\hline sp|Q2HJ57 & Coactosin-like protein & COTL1 & 3 & 1.05 & 0.32 \\
\hline sp|P00735 & Prothrombin & F2 & 4 & 2.17 & 0.31 \\
\hline sp|Q2UVX4 & Complement C3 & C3 & 30 & 0.63 & 0.06 \\
\hline $\operatorname{tr} \mid F 1 M M 86$ & complement component C6 precursor & C6 & 1 & 1.18 & 0.76 \\
\hline sp|P81187 & Complement factor B & CFB & 4 & 1.05 & 0.25 \\
\hline $\operatorname{tr|B8Y9T0~}$ & Cumulus cell-specific fibronectin 1 transcript variant & FN1 & 14 & 7.14 & 0.00 \\
\hline sp|Q28085 & Complement factor $\mathrm{H}$ & $\mathrm{CFH}$ & 3 & 1.06 & 0.64 \\
\hline $\operatorname{tr} \mid \mathrm{Q} 5 \mathrm{EA67}$ & Inter-alpha (Globulin) inhibitor $\mathrm{H} 4$ & $\mathrm{IT|H} 4$ & 10 & 4.55 & 0.00 \\
\hline $\operatorname{tr} \mid F 2 \times 043$ & Lactoperoxidase & LPO & 11 & 0.97 & 0.30 \\
\hline $\operatorname{tr} \mid F 1 M N N 7$ & Lipopolysaccharide-binding protein & LBP & 1 & 1.10 & 0.51 \\
\hline sp|Q1ZZU7 & Macrophage migration inhibitory factor & MIF & 7 & 0.96 & 0.41 \\
\hline $\operatorname{tr|B5T254}$ & Peptidoglycan recognition protein 1 & PGLYRP1 & 5 & 1.05 & 0.76 \\
\hline $\operatorname{tr|F4YD22~}$ & Peroxiredoxin 1 & PRDX1 & 2 & 1.00 & 1.00 \\
\hline sp|Q9BG13 & Peroxiredoxin-2 & PRDX2 & 5 & 0.99 & 0.83 \\
\hline $\operatorname{tr|Q8SQ28~}$ & Amyloid protein A & Saa3 & 5 & 2.86 & 0.15 \\
\hline sp|P33046 & Cathelicidin-4 & CATHL4 & 7 & 1.85 & 0.30 \\
\hline $\operatorname{tr|F1N3A1}$ & Thrombospondin-1 & THBS1 & 3 & 3.03 & 0.04 \\
\hline $\operatorname{tr|F1MIN1~}$ & Voltage-dependent anion-selective channel protein 1 & VDAC1 & 2 & 0.92 & 0.69 \\
\hline
\end{tabular}

Pathway enrichment analysis showed that 51 differential proteins participated in 62 pathways. Among them, 8 proteins (COL1A1, CO1A2, COL6A3, COL6A2, COL6A1, FN1, HSPG2 and THBS1) were enriched in the ECM-receptor interaction pathway that serves an important role in tissue and organ morphogenesis and in the maintenance of cell and tissue structure and function, 6 proteins (A2M, FGB, FGA, FGG, HP and LCN2) participated in the complement coagulation cascades pathway. The ITIH4 and FLNA proteins took part in the MAPK signaling pathway. Two proteins FGG and HP upregulated by 16.75- and 5.45- fold in mastitis-infected cow's tissues were involved in S. aureus infection pathway (Table 2 and Additional file 2: Table S3).
DIA analysis (Additional file 6) revealed that complement and coagulation cascade was the KEGG pathway with the highest impact value in which fibrinogen complex (GO:0005577), platelet activation (GO:0030168) and protein binding, bridging (GO:0030674) were the significantly impacted GO Terms.

Focal adhesion, amoebiasis, protein digestion and absorption, and ECM-receptor interaction pathways were also significantly impacted in the DIA analysis. These pathways had in common COL1A1, COL1A2 and FN1 proteins, with activation of skin morphogenesis (GO: 0043589), cartilage development involved in endochondral bone morphogenesis (GO: 0060351), collagen fibril organization (GO: 0030199), platelet activation 
Table 2 Differentially expressed proteins between the healthy and mastitis-infected cows' mammary gland tissues

\begin{tabular}{|c|c|c|c|c|c|}
\hline Accession & Protein names & $\begin{array}{l}\text { Official gene } \\
\text { name }\end{array}$ & $\begin{array}{c}\text { Peptides } \\
(\mathbf{9 5 \% )} \\
\end{array}$ & $\begin{array}{c}\begin{array}{c}\text { Fold-change } \\
(114: 117)\end{array} \\
\end{array}$ & $\begin{array}{l}P \text { value } \\
114: 117 \\
\end{array}$ \\
\hline \multicolumn{6}{|c|}{ Up-regulated proteins in the mastitis group } \\
\hline $\operatorname{tr} \mid F 1 M G W 0$ & Collagen alpha-1(I) chain & COL1A1 & 177 & 3.70 & 0.0001 \\
\hline $\operatorname{tr|E1BB91}$ & Collagen alpha-3(VI) chain & COL6A3 & 100 & 2.99 & 0.0000 \\
\hline sp|P02465 & Collagen alpha-2(I) chain & COL1A2 & 100 & 3.56 & 0.0002 \\
\hline sp|P02769 & Serum albumin OS & ALB & 89 & 2.27 & 0.0000 \\
\hline $\operatorname{tr|F1N169}$ & Filamin-A & FLNA & 51 & 2.61 & 0.0000 \\
\hline $\operatorname{tr} \mid F 1 M Q 37$ & myosin-9 & MYH9 & 49 & 2.23 & 0.0010 \\
\hline $\operatorname{tr|F1N4K8}$ & ENSBTAG00000002278 & FBN1 & 31 & 3.19 & 0.0000 \\
\hline $\operatorname{tr}|\mathrm{E} 1 \mathrm{~B}| 98$ & Collagen alpha-1(VI) chain & COL6A1 & 30 & 2.58 & 0.0026 \\
\hline $\operatorname{tr|D4QBF3}$ & Hemoglobin beta & $\mathrm{HBB}$ & 25 & 3.50 & 0.0000 \\
\hline $\operatorname{tr} \mid F 1 M K G 2$ & collagen alpha-2(VI) chain precursor & COL6A2 & 22 & 2.31 & 0.0032 \\
\hline sp|P02676 & Fibrinogen beta chain & FGB & 22 & 11.48 & 0.0000 \\
\hline tr|A5PJE3 & Fibrinogen alpha chain & FGA & 22 & 8.87 & 0.0000 \\
\hline sp|062654 & Desmin & DES & 20 & 7.24 & 0.0000 \\
\hline sp|Q7SIH1 & Alpha-2-macroglobulin & $\mathrm{A} 2 \mathrm{M}$ & 18 & 3.50 & 0.0000 \\
\hline $\operatorname{tr|F1MER7~}$ & Basement membrane-specific heparan sulfate & HSPG2 & 17 & 1.77 & 0.0180 \\
\hline sp|Q9TTE2 & Decorin & $\mathrm{DCN}$ & 17 & 2.29 & 0.0109 \\
\hline sp|Q27991 & Myosin-10 & MYH10 & 16 & 3.10 & 0.0386 \\
\hline sp|Q9TTE1 & Serpin A3-1 & SERPINA3-1 & 15 & 3.34 & 0.0216 \\
\hline $\operatorname{tr|BOFZM4}$ & Myosin light chain 6 & MYL6 & 15 & 1.67 & 0.0106 \\
\hline $\operatorname{tr|B8Y9T0~}$ & Cumulus cell-specific fibronectin 1 transcript variant & FN1 & 14 & 6.92 & 0.0000 \\
\hline $\operatorname{tr|Q3SZZ9~}$ & Fibrinogen gamma-B chain & FGG & 14 & 16.75 & 0.0000 \\
\hline $\operatorname{tr|Q5EA67~}$ & Inter-alpha (Globulin) inhibitor $\mathrm{H} 4$ & $\mathrm{ITIH} 4$ & 10 & 4.49 & 0.0000 \\
\hline $\operatorname{tr|F1MIQ8~}$ & Biglycan & BGN & 9 & 2.54 & 0.0133 \\
\hline sp|P79134 & Annexin A6 & ANXA6 & 8 & 2.00 & 0.0233 \\
\hline sp|P01967 & Hemoglobin subunit alpha-1 & HBA1 & 8 & 4.41 & 0.0020 \\
\hline sp|Q2TBU0 & Haptoglobin & $\mathrm{HP}$ & 7 & 5.45 & 0.0020 \\
\hline sp|P79105 & Protein S100-A12 & $\mathrm{S} 100 \mathrm{~A} 12$ & 6 & 11.17 & 0.0002 \\
\hline sp|Q2KJH6 & Serpin $\mathrm{H} 1$ & SERPINH1 & 6 & 3.05 & 0.0040 \\
\hline $\operatorname{tr} \mid F 1 M H S 5$ & Protein S100-A9 & S100A9 & 6 & 5.01 & 0.0097 \\
\hline $\operatorname{tr|E1B6Z6~}$ & Neutrophil gelatinase-associated lipocalin & LCN2 & 5 & 3.56 & 0.0049 \\
\hline $\operatorname{tr|F1N076~}$ & ENSBTAG00000012164 & $\mathrm{CP}$ & 4 & 5.81 & 0.0129 \\
\hline sp|P51176 & Protein-glutamine gamma-glutamyltransferase 2 & TGM2 & 4 & 8.32 & 0.0069 \\
\hline sp|P28782 & Protein S100-A8 & S100A8 & 4 & 5.01 & 0.0499 \\
\hline $\operatorname{tr} \mid \mathrm{A} 3 \mathrm{KN} 02$ & HIST1H1C protein & HIST1H1C & 3 & 1.69 & 0.0011 \\
\hline $\operatorname{tr}|\mathrm{F} 1 \mathrm{~N} 3 \mathrm{~A} 1|$ & Thrombospondin-1 & THBS1 & 3 & 3.08 & 0.0434 \\
\hline $\operatorname{tr|F1MTV8}$ & ENSBTAG00000047345 & ENSBTAG00000047345 & 2 & 21.68 & 0.0455 \\
\hline \multicolumn{6}{|c|}{ Down-regulated proteins in the mastitis group } \\
\hline sp|P02662 & Alpha-S1-casein & CSN1S1 & 65 & 0.10 & 0.0011 \\
\hline $\operatorname{tr|F1N2D9}$ & Uncharacterized protein & F1N2D9 & 45 & 0.48 & 0.0000 \\
\hline $\operatorname{tr|B5B0D4}$ & Heat shock protein 90 kDa beta member 1 & HSP90B1 & 32 & 0.12 & 0.0000 \\
\hline $\operatorname{tr|Q9N273~}$ & Kappa-casein (Fragment) & CSN3 & 27 & 0.17 & 0.0018 \\
\hline sp|P02663 & Alpha-S2-casein & CSN1S2 & 25 & 0.19 & 0.0001 \\
\hline
\end{tabular}




\begin{tabular}{|c|c|c|c|c|c|}
\hline $\operatorname{tr} \mid \mathrm{F} 1 \mathrm{MU} 12$ & Keratin, type II cytoskeletal 8 & KRT8 & 24 & 0.27 & 0.0000 \\
\hline sp|P08728 & Keratin, type I cytoskeletal 19 & KRT19 & 18 & 0.27 & 0.0024 \\
\hline $\operatorname{tr} \mid F 1 M L K 0$ & Isocitrate dehydrogenase [NAD] regulatory subunit 1, mitochondrial & $\mathrm{IDH} 1$ & 14 & 0.52 & 0.0036 \\
\hline sp|P17248 & Tryptophanyl-tRNA synthetase, cytoplasmic & WARS & 10 & 0.41 & 0.0019 \\
\hline sp|Q5E946 & Protein DJ-1 & PARK7 & 7 & 0.21 & 0.0096 \\
\hline sp|P00727-2 & Isoform 2 of Cytosol aminopeptidase & LAP3 & 7 & 0.58 & 0.0465 \\
\hline sp|P20000 & Aldehyde dehydrogenase, mitochondrial & $\mathrm{ALDH} 2$ & 7 & 0.43 & 0.0337 \\
\hline sp|P81265 & Polymeric immunoglobulin receptor & PIGR & 6 & 0.20 & 0.0081 \\
\hline sp|P42899 & 605 acidic ribosomal protein P2 & RPLP2 & 5 & 0.35 & 0.0069 \\
\hline $\operatorname{tr} \mid \mathrm{F} 1 \mathrm{~N} 3 \mathrm{Q} 7$ & Apolipoprotein A-IV & APOA4 & 5 & 0.24 & 0.0129 \\
\hline sp|P51977 & Retinal dehydrogenase 1 & $\mathrm{ALDH} 1 \mathrm{~A} 1$ & 5 & 0.34 & 0.0146 \\
\hline $\operatorname{tr} \mid F 1 M D K 4$ & Ethylmalonyl-CoA decarboxylase & $\mathrm{ECHDC1}$ & 5 & 0.19 & 0.0108 \\
\hline $\operatorname{tr} \mid F 1 M Z Q 4$ & Butyrophilin, subfamily 1 , member A1 & BTN1A1 & 3 & 0.17 & 0.0052 \\
\hline $\operatorname{tr} \mid \mathrm{C} 4 \mathrm{~T} 8 \mathrm{~B} 4$ & C-reactive protein & CRP & 3 & 0.25 & 0.0027 \\
\hline
\end{tabular}

(GO: 0030168) and protein binding, bridging (GO: 0030674) GO Terms (Additional file 6).

Some GO Terms related to a specific protein but not to any pathway with a high impact and inhibition were casein, alpha/beta (IPR001588) for alpha-S2B-casein (CSN1S2), cartilage development involved in endochondral bone morphogenesis (GO:0060351) and endochondral ossification (GO:0001958) for HSPG2 and CSN1S1 proteins, platelet activation (GO:0030168) for ALB, and oxidoreductase activity, acting on the aldehyde or oxo group of donors, NAD or NADP as acceptor (GO:0016650/GO:0016903) for ALDH1A1 (Additional file 6).

\section{Validation of two candidate proteins COL1A1 and ITIH4}

Among the identified proteins, two proteins COL1A1 and ITIH4 were considered as interesting protein for further studies. Firstly, the relative expressions of COL1A1 $(\sim 50 \mathrm{kDa})$ and ITIH4 $(\sim 100 \mathrm{kDa})$ in the healthy and mastitis-infected cows' mammary gland tissues were investigated by the Western blotting. The results showed that the expression of two proteins significantly increased in the mastitis-infected group when compared with the healthy control group $(\mathrm{P}<0.05)$. These two proteins were also detected in the mammary gland tissue of two groups by the immunohistochemical staining method (Figure 2). However, it should be considered that the apparent difference of COL1A1 and ITIH4 observed by Western blotting and IHC methods were smaller than that seen by iTRAQ (COL1A1, 177 peptides; ITIH4, 10 peptides), although consistent with the observations made by iTRAQ, respectively, might be due to differences in specificity of the commercially available antibodies used in this work, which are not specific for bovine proteins. In the present study, for example, several collagen alpha family proteins
(COL1A1, COL1A2, COL6A1, COL6A2 and COL6A3) present the similar differentially expressed tendency from 2.31-fold to 3.7-fold (Table 2). Therefore, the quantitative conclusions should be drawn only by means of quantitative proteomic approaches or alternative quantitative assays.

\section{Discussion}

In this study, we performed a comprehensive evaluation of proteomic profile in the mammary glands of cows infected naturally by $S$. aureus, providing new data on the in vivo events occurring in the lactating mammary epithelium during persistent infection. Subsequently, GO enrichment and pathway analyses of proteins in combination with western blotting and immunohistochemistry detection for proteins of interest were focused on the consistent results involved in the immune, inflammatory and defense response for mastitis infection.

Generally, host defense against microbial pathogens requires appropriate coordination of multiple signaling pathways. These pathways are triggered by innate immune recognition of microbial molecules, and initiate an inflammatory cascade that involved recruitment of leukocytes to the site of infection, activation of antimicrobial effector mechanisms and induction of an adaptive immune response [17]. In the present study, we found the global expressed and differentially expressed proteins participated in respective 32 and 62 pathways including MAPK, ECM-receptor interaction, complement and coagulation cascades, and focal adhesion KEGG pathways (Additional file 2: Table S1 and Table S3). MAPK play key roles in activating host innate immune responses and are frequent targets of pathogenic effectors in animal systems [18]. The complement and coagulation cascades are connected to the immune system [19]. Cells of the immune 

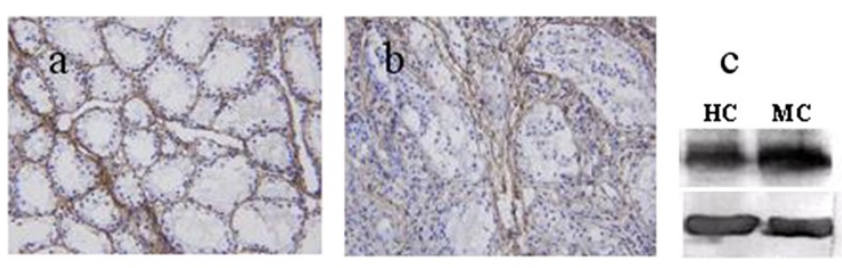

COL1A1
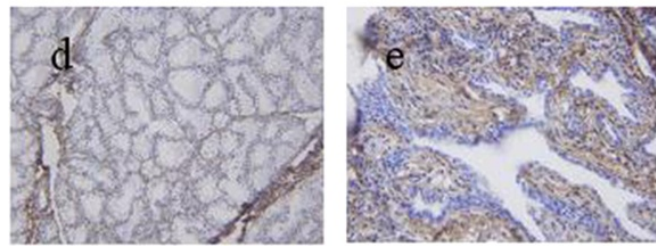

B -Actin

ITIH4

B-Actin

Figure 2 Expression and localization of bovine COL1A1 and ITIH4 proteins. a, b: The localization and expression of COL1A1 in the healthy cow $(\mathrm{HC})$ and mastitis cow's $(\mathrm{MC})$ mammary gland tissues by immunohistochemical staining. Brown indicates the positive COL1A1 protein expression; blue presents the negative. $\mathbf{d}$, e: The localization and expression of ITIH4 in the HC and MC group's mammary gland tissues by immunohistochemical staining. Brown indicates the positive ITIH4 protein; blue presents the negative. $\mathbf{c}$, $\mathbf{f}$ : The results of Western blotting reveal the significant increase of COL1A1 and ITIH4 proteins in MC group compared to HC group $(p<0.05)$.

system are activated by soluble chemokine signals and must migrate through endothelial cell or solid tissue barriers to reach sites of inflammation or infection during the progress of performing host-defense functions. Adhesive interactions of immune cells with endothelium, extracellular matrix components, and cells of solid organs are the critical control point of the immune response. Both the soluble chemokine and cell adhesion receptor-mediated migration signals must converge on common intracellular targets to engage the cell migration machinery [20].

Specifically, in this study, several differentially expressed proteins, such as fibrinogen proteins (FGA, FGB and FGG), complement proteins (C3 and $\mathrm{C} 6$ ) expressed in mammary gland participated in many pathways encompassing the MAPK, complement and coagulation cascades, focal adhesion, etc. The complement system plays a fundamental role in innate immunity in addition to enhancing adaptive immune responses and is therefore a primary line of defense against infection [21]. The beginning of the pathogenesis of mastitis is determined by the binding of $S$. aureus to platelets [22]. This binding is likely to be mediated in part by soluble bridging molecules (GO:0030674) like fibrinogen (GO:0005577) [23], that link the organism to the platelet surface (GO:0030168). Platelets play a key role in innate defenses against Staphylococci by releasing platelet microbicidal proteins that kill many $S$. aureus isolates. Platelet binding may be an important mechanism for host against mastitic infections, because platelets attached to damaged cell surfaces may serve as binding center for organisms circulating in the blood [24]. Moreover, clinical and subclinical mastitis is characterized by abnormalities in the coagulation process due to excessive fibrin deposition in microvasculature leading to clot formation [25]. C3 protein was numerically down-regulated in the mastitic cow's mammary gland with the $\mathrm{p}$ value nearing significance. A2M protein belongs to the complement and coagulation cascades pathway, which has been reported that it is involved in the mastitis susceptibility in our previous publication $[26,27]$.

The combined use of iTRAQ labelling and LC ESI-MS/ MS is a powerful tool for the proteomics identification of the dairy cow's mammary gland tissues. In this study, only 768 proteins were detected in the cow's mammary gland. Whereas, a transcriptome profiling study reveals more than 2,200 differential expressed genes ( $>1.5$-fold) in the Streptococcus uberis-induced mastitis mammary gland when compared with noninfected control quarters [28]. Obviously, the number of proteins is by far, less than the amount of genes at the mRNAs level. The divergence might be caused by these factors, such as distinct response to different bacteria [29] and strain types [9], different infection ways (challenging and naturally occurring), different infection stages (early and late), translation regulation of mRNAs to proteins, or limitation of detection method. On the other hand, the contrasting data between proteomics and transcriptomics analysis, suggests that changes in protein profiles between the healthy and mastitis-infected cows' mammary gland tissues provide information that is complementary to transcriptional profiling studies, revealing potentially crucial aspects of the mastitis infection response. Especially, when the mammary gland was at the state of fibrosis for the serious infection, expression of some proteins associated with metabolism would be shut down.

Three S100 calcium-binding proteins S100 calciumbinding protein A12 (S100A12), S100A8 and S100A9, are involved in the immune, defense and inflammatory responses, and have proinflammatory functions and direct antimicrobial effects [30,31]. It has been reported that there is 5.2 fold to 49.1 fold up-regulation of S100A12 expression for three cows at the infection dose of $1 \times 10^{5} \mathrm{~S}$. aureus 
when compared with the intra-animal controls [32]. Furthermore, significantly increased S100A12 protein expression was detected in the milk whey from the infected udders in all three cows at $16 \mathrm{~h}$ post-infection [32]. In the present study, proteins S100A12, S100A8 and S100A9, were up-regulated by $11.17,5.1$ and 5.1 folds in the mastitis-infected mammary glands, which is consistent with the previous report, further demonstrating their roles in the immune response to pathogen infection.

Type I collagen, which is encoded by two subunits of COL1A1 and one subunit of COL1A2 wound together to form a triple-helix, of which the coordinated transcription rates ensure a 2:1 ratio. It is the most abundant protein in vertebrates and is the main structural protein of skin, bone, teeth, and tendon [33]. Moreover, it plays a major role in tissue and organ development, cell migration, proliferation, and differentiation, wound healing, tissue remodeling, and homeostasis and therefore it participates in the maintenance of organ morphology and function. Its excessive deposition results in the fibrosis of tissues [34].

Bovine mammary glands are composed of glandular tissue and connective tissue. It is easy to understand the most abundant expression of COL1A1. Our finding of type I collagen protein expression is consistent with the above result. During infection of the mammary glands, the tissue damage can initially be caused by bacteria and their products. Certain bacteria like $S$. aureus produce toxins that destroy cell membranes and damage milkproducing tissue, whereas other bacteria are able to invade and multiply within the bovine mammary epithelial cells. Then, more immune cells migrate into the mammary gland and harm the blood-milk barrier. Damage of the mammary epithelium gets worsen and it finally results in fibrosis [35]. Therefore, regulating the bovine COL1A1 expression for reducing tissue damage may be a cost-effective way to reduce the losses caused by mastitis.

Focal adhesion, amoebiasis, ECM receptor interacting and protein digestion and absorption pathways were highly impacted due to the activation of several proteins that might have a role in the conformational changes in the parenquimal epithelial cells due to $S$. aureus infection (Additional file 5). Heparan sulfate proteoglycan 2 (HSPG2) or perlecan blocks endothelial cell adhesion to fibronectin and type I collagen in the submucosal connective tissue from the parenquimal tissue of the infected mammary gland. Fibronectin plays a major role in cell adhesion, growth, migration and differentiation, and it is important for processes such as wound healing [36]. Altered fibronectin expression has been associated with fibrosis [37]. Milk obtained from cows with clinical mastitis possessed high counts of somatic cells and very high levels of protease activity which hydrolyzes casein [38]. This process was also detected by DIA analysis by a high impacted inhibition of caseins (IPR001588).
The acute-phase response occurs in animals and elevates APP as a consequence of infection, inflammation, or trauma. APP including serum amyloid A, haptoglobin, alpha-1-acid glycoprotein, alpha-1-proteinase inhibitor (alpha-1-antitrypsin) and ITIH4 have been shown to increase in different inflammatory processes, in both in vivo and in vitro models, and involved several inflammatory diseases, such as Crohn's disease and ulcerative colitis [39-41]. ITIH4 protein is a $120 \mathrm{KD}$ glycoprotein, which is prone to be cleaved to produce fragments of different length, such as $100 \mathrm{kDa}$ and $35 \mathrm{kDa}$ fragment, which have been identified as the biomarkers for Down syndrome [41], amyotrophic lateral sclerosis [42], and cancer [43]. A report showed that all heifers responded to the mastitis with increased ITIH4 concentrations [44]. Severely infected heifers showed maximum ITIH4 concentrations at $72 \mathrm{~h}$ after bacterial injection. The concentration of the protein in serum was 6- to 12- fold higher than before the bacterial challenge. In the four animals with milder clinical mastitis, the protein exhibited only a three- to four-fold increase during the infection process and had reached a plateau by $48 \mathrm{~h}$ after the challenge. In both cases, the ITIH4 concentrations decreased to normal values about 2 weeks after the injection [44]. In this study, however, at the late stage of infection, the ITIH4 protein was first found to be significantly increased in the mammary gland tissues as compared to the control case. In this study, iTRAQ method is unable to differentiate cleaved fragments from whole protein. The result of western blotting implies that $100 \mathrm{kDa}$ fragment of bovine ITIH4 plays an important role in the defense and immune responses to infection of mastitis.

\section{Conclusion}

Proteomics analysis highlighted the effects of proteins like collagen, fibrinogen, fibronectin, casein alpha and heparan sulfate proteoglycan 2 among others in mammary gland tissues infected naturally by $S$. aureus. This study also established a protein database characteristic of the mammary response during late on-set of $S$. aureus naturally occurring mastitis. The iTRAQ technology and LC-MS/MS data generated, can be used as a reference for further research in this field.

Ours is the first to examine the late response to natural mastitis providing a 'closer look' into the mechanisms associated with host tissue damage. The differentially expressed proteins we discovered in this study, such as COL1A1 and ITIH4, may serve as potential genes for the susceptibility to mastitis in dairy cows.

\section{Methods}

\section{Ethics statement}

All experiments were carried out according to the Regulations for the Administration of Affairs Concerning Experimental Animals published by the Ministry of Science 
and Technology, China in 2004 and approved by the Animal Care and Use Committee from the Dairy Cattle Research Center, Shandong Academy of Agricultural Sciences, Shandong, P. R. China.

\section{Animals}

Tissue samples were collected from mammary glands of first lactation Chinese Holstein cows (3.0- to 3.5-year-age) from the farm of the Dairy Cattle Research Center, Shandong Academy of Agricultural Sciences. The milk somatic cell count (SCC) of cows was measured by the instrument Fossomatic 5000 (Foss Electric, Denmark) once a month as part of the DHI program. Meanwhile pathogens in milk for each quarter were identified using cultures. First, the cows with the SCC $>5 \times 10^{6}$ cells $/ \mathrm{mL}$ and California mastitis test CMT score $\geq 2$ were considered as the candidate individuals. In the end of the first month (The second milk sampling), we did not find any pathogen infection by culturing from milk samples. These candidate cows were treated with antibacterial drugs when they occurred elevated SCC along with S. aureus infection in milk cultures after two months (The third milk sampling). After approximately three months, the subclinical cows that developed into clinical mastitis as identified by abnormalities in the udder such as swelling, redness, hardness or pain clinical symptoms, had to be culled for the ineffective treatments. Thus, these cows with only the $S$. aureus infection were selected to provide the mastitic samples. The mastitic group used for this study was defined as those cows with $S$. aureus strain, designated $\mathrm{zfb}$ strain which is resistant to methicillin and could not produce lipase when compared with the ATCC 25923 standard strain. The colony morphology of $S$. aureus capsule was diffuse in vivo and in vitro when it was cultured in modified serum soft agar. At slaughter one tissue sample was collected then frozen in liquid nitrogen, and stored at $-80^{\circ} \mathrm{C}$ for further protein analysis. Another fresh tissue sample was collected for pathogen identification described as our previous procedures $[45,46]$. A cow was defined as healthy if the above clinical symptoms were not observed and the milk SCC was lower than $1 \times 10^{5}$ cells $/ \mathrm{mL}$, and no pathogens were examined from the cow's mammary tissues using culture and PCR methods [45]. After pathological evaluation, mammary gland tissues of 3 healthy and 3 mastitisinfected cows at a similar stage of lactation were categorized in the control and case groups. These samples were used for the iTRAQ, Western blotting and Immunohistochemistry analyses.

\section{Protein isolation and iTRAQ labeling}

To each $0.5 \mathrm{~g}$ tissue sample was added $10 \%$ polyvinylpyrrolidone prior to grinding in liquid nitrogen. Then, the supernatant was transferred to another tube and five folds $10 \%$ chilled TCA acetone added for $2 \mathrm{hrs}$ at $-20^{\circ} \mathrm{C}$. The precipitation was washed with chilled acetone for 30 mins, and the supernatant was discarded after centrifugation at $4^{\circ} \mathrm{C}, 20000 \times \mathrm{g}$ for $20 \mathrm{mins}$. The above steps were repeated 3 times. The pellet was dried in the air, then dissolved in $500 \mu \mathrm{l} 0.5 \mathrm{M}$ TEAB and sonicated at 200 Watts for 15 mins. Then it was centrifuge at 4, $30000 \mathrm{~g}$ for $20 \mathrm{mins}$ and the supernatant was quantified for protein using the GE Healthcare's Quant kit (Code No. 80-6483-56).

A total of $100 \mu \mathrm{g}$ protein for each sample was digested with Trypsin Gold (Promega) at a ratio of protein:trypsin of $20: 1$ at $37^{\circ} \mathrm{C}$ for 4 hrs. After trypsin digestion, the peptides were dried via vacuum centrifugation. The iTRAQ labeling was performed according to the manufacturer's protocol (Applied Biosystems). Briefly, one unit iTRAQ reagent (Applied Biosystems) was thawed and reconstituted in $70 \mu \mathrm{L}$ isopropanol. The healthy and mastitis groups were labeled with 117 and 114 iTRAQ reagent, respectively, by incubation at room temperature for $2 \mathrm{hrs}$. The labeled peptide samples were pooled and fractionated by strong cationic exchange (SCX) chromatography.

\section{Fractionation by SCX}

For SCX chromatography using the LC-20AB HPLC Pump system (Shimadzu), the peptide from digestion was reconstituted with $4 \mathrm{~mL}$ buffer A ( $25 \mathrm{mM} \mathrm{NaH} 2 \mathrm{PO} 4$ in $25 \% \mathrm{ACN}, \mathrm{pH} 2.7$ ) and loaded onto a $4.6 \times 250 \mathrm{~mm}$ Ultremex SCX column containing $5-\mu \mathrm{m}$ particles (Phenomenex, CA, USA). The peptides were eluted at a flow rate of $1 \mathrm{~mL} / \mathrm{min}$ with a gradient of buffer $A$ for 10 min, 5-35\% buffer B (25 mM NaH2PO4, $1 \mathrm{M} \mathrm{KCl}$ in 25\% ACN, pH2.7) for $11 \mathrm{~min}, 35-80 \%$ buffer B for $1 \mathrm{~min}$. The system was then maintained in $80 \%$ buffer $B$ for 3 min before equilibrating with buffer A for 10 min prior to the next injection. Elution was monitored by measuring absorbance at $214 \mathrm{~nm}$, and fractions collected every $1 \mathrm{~min}$. The eluted peptides were pooled as 10 fractions, desalted by Strata X C18 column (Phenomenex, CA, USA) and vacuum-dried.

\section{LC-ESI-MS/MS analysis by LTQ-Orbitrap HCD}

Each fraction was resuspended in $1 \mathrm{~mL}$ of buffer $\mathrm{A}$ ( $2 \% \mathrm{ACN}, 0.1 \% \mathrm{FA}$ ) and centrifuged at $20000 \mathrm{~g}$ for $10 \mathrm{~min}$. In each fraction, the final concentration of peptide was about $0.5 \mu \mathrm{g} / \mathrm{ul}$ on average. Ten $\mu \mathrm{l}$ supernatant was loaded on a Shimadzu LC-20 AD nanoHPLC by the autosampler onto a $2 \mathrm{~cm} \mathrm{C18}$ trap column (inner diameter $200 \mu \mathrm{m}$ ) and the peptides were eluted onto a resolving $10 \mathrm{~cm}$ analytical C18 column (inner diameter $75 \mu \mathrm{m}$ ) made in-house. The samples were loaded at $15 \mu \mathrm{L} / \mathrm{min}$ for $4 \mathrm{~min}$, and then the $44 \mathrm{~min}$ gradient was run at $400 \mu \mathrm{L} / \mathrm{min}$ starting from 2 to $35 \% \mathrm{~B}$ (98\% ACN, 0.1\% FA), followed by 2 min linear gradient to $80 \%$, and maintenance at $80 \%$ $\mathrm{B}$ for $4 \mathrm{~min}$, and finally returned to $2 \%$ in $1 \mathrm{~min}$. 
The peptides were subjected to nanoelectrospray ionization followed by tandem mass spectrometry (MS/MS) in an LTQ Orbitrap Velos (Thermo Fisher, MA, USA) coupled online to the HPLC (Shimadzu, Kyoto, Japan). Intact peptides are detected in the Orbitrap at a resolution of 60000. Peptides were selected for MS/MS using high energy collision dissociation (HCD) operating mode with a normalized collision energy setting of $45 \%$; ion fragments were detected in the LTQ. A data-dependent procedure that alternated between one MS scan followed by eight MS/MS scans was applied for the eight most abundant precursor ions above a threshold ion count of 5000 in the MS survey scan with the following Dynamic Exclusion settings: repeat counts, 2; repeat duration, 30s; and exclusion duration, $120 \mathrm{~s}$. The electrospray voltage applied is $1.5 \mathrm{kV}$. Automatic gain control (AGC) was used to prevent overfilling of the ion trap; $1 \times 10^{4}$ ions were accumulated in the ion trap for generation of HCD spectra. For MS scans, the $\mathrm{m} / \mathrm{z}$ scan range was 350 to $2000 \mathrm{Da}$. The experiment was repeated three times, and the results were categorized as 114 and 117 groups.

\section{Database search and quantification}

The MS/MS data were searched against the uniprot_Bovidae $(43,204$ sequences) database for peptide identification and quantification using the ProteinPilot software 4.0 (Applied Bio-system, USA). The parameters were set as follows: trypsin as enzyme, methylmethanethio sulphonate of cysteines residues as fixed modification. The Paragon Algorithm (Applied Biosystem, USA) followed by the ProGroup Algorithm (Applied Biosystem, USA) were applied to remove redundant hits to determine the target proteins. Other parameters such as fragment ion accuracy, tryptic cleavage specificity, and allowance for number of missed cleavages were provided and processed by ProteinPilot software. Unused Prot-Score $>1.3$ (95\%) as threshold with at least more than one peptide above the $95 \%$ confidence was considered as benchmark for protein identification.

\section{Electrophoresis and Western blotting}

Proteins were extracted from six samples including three healthy and three mastitis-infected mammary gland tissues of Chinese Holstein cows for Western blot analysis. Pre-stained molecular weight standards (Thermo, USA) were included on all gels as a reference. Samples were separated by sodium dodecyl sulfate-polyacrylamide gel electrophoresis (SDS-PAGE, Beyotime, China) on 5\% and $12 \%$ polyacrylamide gels, and subsequently transferred to polyvinylidene difluoride (PVDF) membrane (Millipore, USA). Following blocking with blocking buffer (Beyotime, China) for $1 \mathrm{~h}$ at RT, western blots were probed with rabbit polyclonal Collagen I (Abcam, $1: 1000$ dilution) and mouse monoclonal $\beta$-actin primary antibody (Beyotime, 1:1000 dilution), followed by Horseradish Peroxidase (HRP) labeled goat anti-rabbit IgG (Beyotime, 1:1000 dilution) secondary antibody. The goat polyclonal to mouse ITIH4 (synthetic peptide: KPEGQEQFQVAEK; ab118283) was used as the primary anti-body for the bovine ITIH4 protein of WB. The blots were developed using a Horseradish Peroxidase Color Development Kit (DAB, Beyotime, Nantong, China). Image analysis was performed with Quantity one (Bio-Rad, CA, USA).

Table 3 Networks ranking with relative molecules symbols list, score value, number of molecules belonging to the dataset (Focus molecules) and top function for each network

\begin{tabular}{|c|c|c|c|c|}
\hline ID & Molecules in network & Score & $\begin{array}{c}\text { Focus } \\
\text { molecules }\end{array}$ & Top functions \\
\hline 1 & $\begin{array}{l}\text { A2M, ALB, ALDH2, ALDH1A1, Alp, Alpha catenin, ANXA6, Ap1, APOA4, calpain, chymotrypsin, } \\
\text { COL1A1, COL1A2, COL6A1, COL6A2, COL6A3, collagen, Collagen Alpha1, Collagen type I, } \\
\text { Collagen type III, Collagen type IV, Collagen type VI, Collagen(s), CP, DCN, DES, elastase, ERK1/2, } \\
\text { FBN1, FGA, FGB, FGG, Fibrin, Fibrinogen, FLNA, FN1, Focal adhesion kinase, GPIIB-IIIA, Growth } \\
\text { hormone, HBA1/HBA2, HDL, HP, HSPG2, IL1, Immunoglobulin, Integrin, ITIH4, KRT8, Laminin, } \\
\text { Ldh, LDL, Mmp, P38 MAPK, Pak, Pdgf (complex),PDGF BB, Pka, Rock, S100A9, S100A12, } \\
\text { SERPINA3, SERPINH1, Smad, Stat3-Stat3, T3-TR-RXR, Tgf beta, TGM2, THBS1, trypsin, Vegf }\end{array}$ & 68 & 31 & $\begin{array}{c}\text { Organismal Injury and } \\
\text { Abnormalities, Dermatological } \\
\text { Diseases and Conditions, } \\
\text { Hereditary Disorder }\end{array}$ \\
\hline 2 & $\begin{array}{l}\text { Actin, ADCY, ADM, Akt, Alpha Actinin, ANGPTL1, caspase, CD3, CD27, CD226, CSK, Cytokeratin, } \\
\text { D-mannose, ERK, F Actin, Fascin, FKBP1A, GCNT1, GRB7, HBB, hemoglobin, HIST1H1C, Histone } \\
\text { h3, Ige, Igf, IgG, IL12 (complex), IL17R, II3r, Insulin, ITGB8, Jnk, KRT19, L-isoleucine, LCN2, LCP1, } \\
\text { LYPLA1, MAPK13, Mapk, MAZ, MB, MYBPH, MYH9, MYH10, MYL1, MYL4, MYL6, MYO15A, Myosin, } \\
\text { NEB, NFkB (complex), PER1, PI3, PI3K (complex), PIGR, PkC(s), PLA2R1, PTPRCAP, PVRL2, Rac, Ras, } \\
\text { S100, S100A8, S100A12, SLC5A3, SORBS1, Sos, TCR, TLR2/TLR4, TMPRSS6 }\end{array}$ & 25 & 14 & $\begin{array}{c}\text { Lymphoid Tissue Structure } \\
\text { and Development, Organ } \\
\text { Morphology, Cancer }\end{array}$ \\
\hline 3 & $\begin{array}{l}\text { AKT1, ALDH1B1, ATP5J2, Casein, COPS8, CORO1B, CPB2, Csn1s1, DAZAP1, DDX18, DIMT1, } \\
\text { Fascin, FGA, GAR1, GLUD1, GPI, HNRNPA1L2, Igf, II3r, IPO4, ITGAX, ITGB8, KIAA1524, KIDINS220, } \\
\text { LAP3, LCP1, MDN1, MMP16, MRPS34, MT-CYB, MTHFR, MTM1, MYBPH, MYC, MYL1, NDUFA5, } \\
\text { NDUFS2, NOP58, NUAK1, NUP205, PDCD11, PELI2, PGS1, PI4KA, PPA1, PVRL2, SAP130, SEC22B, } \\
\text { SLC1A4, SLC20A1, SLC25A1, SLC40A1, SORBS1, SRM, ST6GAL1, Thbs1, THBS2, TIA1, TIAL1, TNF, } \\
\text { Top2, TRAP1, UBC, UNC5B, UQCR10, UQCR11, UQCRB, UQCRFS1, Wap, YARS }\end{array}$ & 12 & 8 & $\begin{array}{l}\text { Cell Cycle, Cardiovascular } \\
\text { Disease, Cell Morphology }\end{array}$ \\
\hline 4 & CLDN24,cldn & 2 & 1 & \\
\hline
\end{tabular}




\section{Immunohistochemistry (IHC)}

Mammary gland tissues from healthy and mastitis-infected cows were fixed in $4 \%$ paraformaldehyde PFA, and then all tissues were embedded in paraffin and sectioned for IHC test as described previously [47]. Briefly, a total of $1 \mathrm{~L}$ deionized water and $10 \mathrm{~mL}$ citrate buffer solution were used to rehabilitate antigen and washed with $0.01 \mathrm{M}$ PBS (PH 7.4) twice per $3 \mathrm{~min}$. Then, immunoreaction slides were deparaffinaged and hydrated. The slides were blocked with endogenous peroxydase for $10 \mathrm{~min}$ and subsequently washed with PBS and incubated with rabbit polyclonal Collagen I (1:100; Abcam, HK, China) and goat polyclonal to ITIH4 (1:100; Abcam, HK, China) for $60 \mathrm{~min}$ at RT. After washing with $\mathrm{PBS}$, the slides were incubated with anti-mouse secondary antibody for $10 \mathrm{~min}$ at RT. Next, the antibody was visualized with $0.6 \mathrm{mg} / \mathrm{mL}$ 3,3'-diaminobenzidine tetrachloride (DAB, Cwbiochem, Beijing, China) Horseradish Peroxidase color development kit (Cwbiochem, Beijing, China) for brown staining under the microscope (Leica LB30T, Germany) according to the manufacturer's instruction. Finally, the slides were re-stained with hematoxylin (Cwbiochem, Beijing, China) and dried again. Images were captured using a digital camera (Leica, Wetzlar, Germany).

\section{Bioinformatics}

The cellular component (CC), molecular function (MF) and biological process (BP) of the proteins identified by

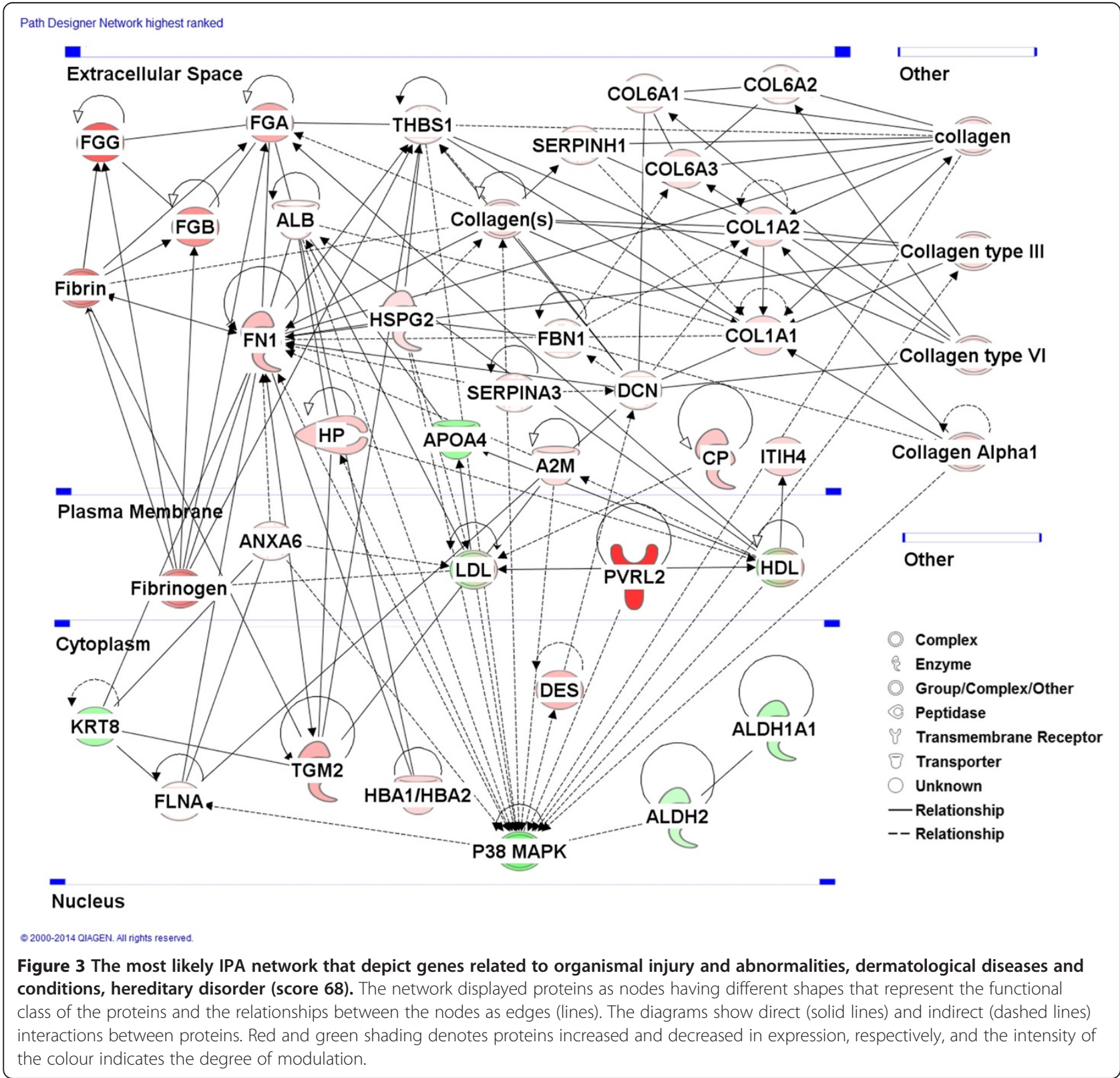


iTRAQ were annotated by the Blast2GO software (http:// www.blast2go.org/); GO functional classification and enrichment analysis were also performed to identify GO terms that were significantly enriched in differentially expressed proteins using DAVID analysis (http://david.abcc.ncifcrf.gov/).

We used two different bioinformatic tools to examine the functional relationships among the differentially expressed proteins (DEP): the Dynamic Impact Approach (DIA) and the Ingenuity Pathway Analysis tool version 8.0 (IPA; Ingenuity ${ }^{\circ}$ Systems, Inc, Redwood City, CA, http:// www.ingenuity.com). Canonical pathway and regulatory network analyses were computed with IPA, using as a reference set the Ingenuity Pathways Knowledge Base. To identify the cellular mechanisms most related to mastitis, we searched the Ingenuity Pathways Knowledge Base for networks of interconnected modulated proteins, and for overrepresented pathways. IPA is a software created to identify the most significant biological functions, canonical pathways, and networks embedded in a protein/gene set. The list was then uploaded into the IPA software that mapped and annotated 54 proteins, all involved in 3 main networks. IPA ranked networks depending on the reliability of the microarray results on the basis of prior published data. The statistical likelihood (Score) was used to rank the networks and ranged between 65 and 2 (Table 3 and Figure 3).

To enhance the biological interpretation of the results, we used the DIA with the 55 differentially expressed proteins identified, considering in the analysis: KEGG pathways, each of the three main GO categories (BP, MF and CC) and, for predicting the presence of domains and important sites within proteins (INTERPRO).

For DIA analysis, information from the freely-available online databases KEGG and DAVID (v6.7) was considered. A list of protein or gene identifiers (Entrez Gene IDs) from Bos taurus was uploaded all at once to extract and summarize functional annotations associated with groups of proteins or with each individual protein. Details of the DIA approach and its validation have been reported previously [15]. The direction of the impact ("flux") was calculated according to our published procedure [48], considering negative flux values as inhibited or downregulated and positive flux values as activated or upregulated. The impact value determines the biological significance of the change on a pathway and/or function by a treatment and/or change in physiological state. For this study, due to the abundance of significant GO terms and KEGG pathways from the DIA output, we considered as significant or more relevant from a biological standpoint those with calculated impact values above $30 \%$ of the total impact value of the top-impacted pathways.

\section{Statistical analysis}

In the iTRAQ analysis, the relative expression of proteins was based on the ratio of the reporter ions of the peptides
(114:117) using the Mascot software. We adopted the fold change to compare with the differentially expressed proteins. T-test was used to analyze the p-value of the value of $\log _{2}(114 / 117)$. Moreover, the protein with the fold change cutoff ratio $<0.66$ or $>1.50$ as well as the $p$ value less than 0.05 was designated the differential expression protein. In the WB analysis, the Student's $t$-test was used to compare means between two groups. Statistical analyses were conducted with SPSS 11.0 (SPSS, Chicago, IL, USA), and a two-tailed $\mathrm{p}<0.05$ was considered significant.

\section{Additional files}

Additional file 1: Summaries of peptide and protein identification.

Additional file 2: Table S1. KEGG pathway analysis of the expressed proteins in mammary gland of cows by DAVID. Table S2: GO term of differential proteins for BP by Blast2GO. Table S3: Pathway analysis of differential proteins by Blast2GO.

Additional file 3: Figure S1. GO terms of differentially expressed proteins for CC by Blast2GO.

Additional file 4: Figure S2. GO terms of differentially expressed proteins for MF by Blast2GO.

Additional file 5: Figure S3. GO terms of differentially expressed proteins for BF by Blast2GO.

Additional file 6: DIA analysis of expressed proteins in mammary gland tissues. Biological Process (BP), Molecular Function (MF), Cellular Component (CC) or Interpro (IPRO) related to those pathways for mastitic vs. healthy cows. Flux represent the direction of each pathway (green color $=$ inhibition, yellow color $=$ stable, red color $=$ activation with different color intensities according with the level of up-regulation or down-regulation). Blue lines show the impact of each GO Term.

\section{Competing interests}

The authors declare that they have no competing interests.

\section{Authors' contributions}

JMH was responsible for designing and conducting the experiment analysis, interpretation of data, drafting the manuscript and as the corresponding author. GJL, ZJZ and XGW has contributed to the iTRAQ preparation and expression analysis of genes. CQ, YZ RLL, JBL, CFW and WJY have contributed by helping the preparation and collection of samples. GJL, XGW, YXX and ZHJ contributed to $I H C$ experiment. SJM and JJL has contributed data analysis and helped to draft and polish the manuscript. JFZ has contributed to the design, reading of the draft manuscript, providing experiment platform and has contributed as the corresponding author. All contributing authors have reviewed the manuscript and approved the submitting of final manuscript.

\section{Acknowledgments}

This study was supported by grants from the National Natural Science Foundation of China $(31371255 ; 31271328)$, Youth Talents Training Program of Shandong Academy of Agricultural Sciences (SAAS-YTTP-2014), the Support Program of the Ministry of Science and Technology, P. R. China (2011BAD19B02 and 2011BAD19B04), the Major Project of National Transgene in China (2014ZX08007-001), and the Program of National Cow Industrial Technology System (CARS-37).

\section{Author details}

'Dairy Cattle Research Center, Shandong Academy of Agricultural Sciences, No.159 North of Industry Road, Jinan, Shandong 250131, China. ${ }^{2}$ College of Animal Science and Technology, Nanjing Agricultural University, Nanjing 210095, China. ${ }^{3}$ Mammalian NutriPhysioGenomics, Department of Animal Sciences, University of Illinois, Urbana, IL 61801, USA. ${ }^{4}$ Division of Nutritional Sciences, University of Illinois, Urbana, IL 61801, USA. ${ }^{5}$ Department of Animal Sciences, University of Illinois, Urbana, IL 61801, USA. 
Received: 19 January 2014 Accepted: 26 September 2014

Published: 2 October 2014

\section{References}

1. Viguier C, Arora S, Gilmartin N, Welbeck K, O'Kennedy R: Mastitis detection: current trends and future perspectives. Trends Biotechnol 2009, 27:486-493.

2. Huang JM, Wang HM, Wang CF, Li JB, Li QL, Hou MH, Zhong JF: Single nucleotide polymorphisms, haplotypes and combined genotypes of lactoferrin gene and their associations with mastitis in Chinese Holstein cattle. Mol Biol Rep 2010, 37:477-483.

3. Hogeveen HPS, Persson-Waller K, Hogan JS, Lam TJGM, Oliver SP, Schukken YH, Barkema HW, Hillerton JE: Current status and future challenges in mastitis research. Proc Natl Mastitis Council 2011, 50:36-48.

4. Lippolis JD, Reinhardt TA, Kehrli ME Jr: Proteomics of mastitis causing Escherichia coli. Proc Natl Mastitis Council 2009, 48:236-237.

5. Baeker R, Haebel S, Schlatterer K, Schlatterer B: Lipocalin-type prostaglandin $\mathrm{D}$ synthase in milk: a new biomarker for bovine mastitis. Prostaglandins Other Lipid Mediat 2002, 67:75-88.

6. Boehmer JL: Proteomic analyses of host and pathogen responses during bovine mastitis. J Mammary Gland Biol Neoplasia 2011, 16:323-338.

7. Alonso-Fauste I, Andrés M, Iturralde M, Lampreave F, Gallart J, Alava MA: Proteomic characterization by 2-DE in bovine serum and whey from healthy and mastitis affected farm animals. J Proteomics 2012, 75:3015-3030.

8. Roncada P, Piras C, Soggiu A, Turk R, Urbani A, Bonizzi L: Farm animal milk proteomics. J Proteomics 2012, 75:4259-4274.

9. Kim Y, Atalla H, Mallard B, Robert C, Karrow N: Changes in Holstein cow milk and serum proteins during intramammary infection with three different strains of Staphylococcus aureus. BMC Vet Res 2011, 7:51.

10. Reinhardt TA, Sacco RE, Nonnecke BJ, Lippolis JD: Bovine milk proteome: quantitative changes in normal milk exosomes, milk fat globule membranes and whey proteomes resulting from Staphylococcus aureus mastitis. J Proteomics 2013, 82:141-154.

11. Mansor R, Mullen W, Albalat A, Zerefos P, Mischak H, Barrett DC, Biggs A Eckersall PD: A peptidomic approach to biomarker discovery for bovine mastitis. J Proteomics 2013, 85:89-98.

12. Loor JJ, Moyes KM, Bionaz M: Functional adaptations of the transcriptome to mastitis-causing pathogens: the mammary gland and beyond. J Mammary Gland Biol Neoplasia 2011, 16:305-322.

13. Jensen K, Günther J, Talbot R, Petzl W, Zerbe H, Schuberth HJ, Seyfert HM, Glass EJ: Escherichia coli- and Staphylococcus aureus-induced mastitis differentially modulate transcriptional responses in neighbouring uninfected bovine mammary gland quarters. BMC Genomics 2013, 14:36.

14. Zhao $X$, Lacasse P: Mammary tissue damage during bovine mastitis: causes and control. J Anim Sci 2008, 86:57-65.

15. Wiese S, Reidegeld KA, Meyer HE, Warscheid B: Protein labeling by iTRAQ: a new tool for quantitative mass spectrometry in proteome research. Proteomics 2007, 7:340-350.

16. Bionaz M, Periasamy K, Rodriguez-Zas SL, Everts RE, Lewin HA, Hurley WL, Loor Jj: Old and new stories: revelations from functional analysis of the bovine mammary transcriptome during the lactation cycle. PLoS One 2012, 7:e33268.

17. Brodsky IE, Medzhitov R: Targeting of immune signaling networks by bacterial pathogens. Nature Cell Biol 2009, 11:521-527.

18. Young JA, Dillin A: MAPping innate immunity. Proc Natl Acad Sci U S A 2004, 101:12781-12782.

19. Oikonomopoulou K, Ricklin D, Ward PA, Lambris JD: Interactions between coagulation and complement-their role in inflammation. Semin Immunopathol 2012, 34:151-165.

20. Hauck CR, Klingbeil CK, Schlaepfer DD: Focal adhesion kinase functions as a receptor-proximal signaling component required for directed cell migration. Immunol Res 2000, 21:293-303.

21. Carroll MC: Complement and humoral immunity. Vaccine 2008 26(Suppl 8):128-133.

22. Fitzgerald JR, Loughman A, Keane F, Brennan M, Knobel M, Higgins J, Visai L, Speziale P, Cox D, Foster TJ: Fibronectin-binding proteins of Staphylococcus aureus mediate activation of human platelets via fibrinogen and fibronectin bridges to integrin GPIIb/llla and lgG binding to the FcgammaRlla receptor. Mol Microbiol 2006, 59:212-230.

23. Cheung AL, Krishnan M, Jaffe EA, Fischetti VA: Fibrinogen acts as a bridging molecule in the adherence of Staphylococcus aureus to cultured human endothelial cells. J Clin Invest 1991, 87:2236-2245.
24. Yeaman MR, Norman DC, Bayer AS: Platelet microbicidal protein enhances antibiotic-in-duced killing of and postantibiotic effect in Staphylococcus aureus. Antimicrob Agents Chemother 1992, 36:1665-1670.

25. Radostits OM, Gay CC, Hinchcliff KW, Constable PD: A Textbook of the Diseases of Cattle, Horses, Sheep, Pigs, and Goats. 10th edition. Phyladelphia, PA, USA: Saunders Ltd.; 2007.

26. Wang $X G$, Huang JM, Zhao LH, Wang CF, Ju ZH, Li QL, Qi C, Zhang Y, Zhang Z, Zhang W, Hou MH, Yuan JD, Zhong JF: The exon 29 c.3535A > T in the alpha-2-macroglobulin gene causing aberrant splice variants is associated with mastitis in dairy cattle. Immunogenetics 2012, 64:807-816.

27. Wang $X G$, Huang JM, Feng MY, Ju ZH, Wang CF, Yang GW, Yuan JD, Zhong JF: Regulatory mutations in the A2M gene are involved in the mastitis susceptibility in dairy cows. Anim Genet 2014, 45:28-37.

28. Swanson KM, Stelwagen K, Dobson J, Henderson HV, Davis SR, Farr VC, Singh K: Transcriptome profiling of Streptococcus uberis-induced mastitis reveals fundamental differences between immune gene expression in the mammary gland and in a primary cell culture model. J Dairy Sci 2009, 92:117-129.

29. Gilbert FB, Cunha P, Jensen K, Glass EJ, Foucras G, Robert-Granié C, Rupp R, Rainard P: Differential response of bovine mammary epithelial cells to Staphylococcus aureus or Escherichia coli agonists of the innate immune system. Vet Res 2013, 44:40.

30. Boehmer JL, Bannerman DD, Shefcheck K, Ward JL: Proteomic analysis of differentially expressed proteins in bovine milk during experimentally induced Escherichia coli mastitis. J Dairy Sci 2008, 91:4206-4218.

31. Genini S, Badaoui B, Sclep G, Bishop SC, Waddington D, van der Laan MH P. Klopp C, Cabau C, Seyfert HM, Petzl W, Jensen K, Glass EJ, de Greeff A, Smith HE, Smits MA, Olsaker I, Boman GM, Pisoni G, Moroni P, Castiglioni B, Cremonesi P, Del Corvo M, Foulon E, Foucras G, Rupp R, Giuffra E: Strengthening insights into host responses to mastitis infection in ruminants by combining heterogeneous microarray data sources. BMC Genomics 2011, 12:225.

32. Lutzow YC, Donaldson L, Gray CP, Vuocolo T, Pearson RD, Reverter A, Byrne KA, Sheehy PA, Windon R, Tellam RL: Identification of immune genes and proteins involved in the response of bovine mammary tissue to Staphylococcus aureus infection. BMC Vet Res 2008, 4:18

33. Viguet-Carrin S, Garnero P, Delmas PD: The role of collagen in bone strength. Osteoporos Int 2006, 17:319-336.

34. Beauchef $\mathrm{G}$, Bigot N, Kypriotou M, Renard E, Porée B, Widom R, Dompmartin-Blanchere A, Oddos T, Maquart FX, Demoor M, Boumediene K, Galera P: The p65 subunit of NF-kappaB inhibits COL1A1 gene transcription in human dermal and scleroderma fibroblasts through its recruitment on promoter by protein interaction with transcriptional activators (c-Krox, Sp1, and Sp3). J Biol Chem 2012, 287:3462-3478.

35. Grinnell F: Fibronectin and wound healing. J Cell Biochem 1984, 26:107-116.

36. Williams CM, Engler AJ, Slone RD, Galante LL, Schwarzbauer JE: Fibronectin expression modulates mammary epithelial cell proliferation during acinar differentiation. Cancer Res 2008, 68:3185-3192.

37. Andrews AT: Breakdown of caseins by proteinases in bovine milks with high somatic cell counts arising from mastitis or infusion with bacterial endotoxin. J Dairy Res 1983, 50:57-66.

38. Eckersall PD, Young FJ, McComb C, Hogarth CJ, Safi S, Weber A, McDonald T, Nolan AM, Fitzpatrick JL: Acute phase proteins in serum and milk from dairy cows with clinical mastitis. Vet Res 2001, 148:35-41.

39. Hirvonen J, Pyörälä S, Jousimies-Somer H: Acute phase response in heifers with experimentally induced mastitis. J Dairy Res 1996, 63:351-360

40. Jostins L, Ripke S, Weersma RK, Duerr RH, McGovern DP, Hui KY, Lee JC, Schumm LP, Sharma Y, Anderson CA, Essers J, Mitrovic M, Ning K, Cleynen I, Theatre E, Spain SL, Raychaudhuri S, Goyette P, Wei Z, Abraham C, Achkar $J P$, Ahmad T, Amininejad L, Ananthakrishnan AN, Andersen V, Andrews JM, Baidoo L, Balschun T, Bampton PA, Bitton A, et al: Host-microbe interactions have shaped the genetic architecture of inflammatory bowel disease. Nature 2012, 491:119-124.

41. Elliott-Friend J: Investigation into inter-alpha trypsin inhibitor heavy chain $4(\mathrm{ITIH} 4)$ as a biomarker for prenatal screening of Down syndrome using maternal plasma samples. Plymouth Student J 2011, 4:3-29.

42. Tanaka H, Shimazawa M, Takata M, Kaneko H, Tsuruma K, Ikeda T, Warita H, Aoki M, Yamada M, Takahashi H, Hozumi I, Minatsu H, Inuzuka T, Hara H: ITIH4 and Gpx3 are potential biomarkers for amyotrophic lateral sclerosis. J Neurol 2013, 260:1782-1797.

43. Mohamed E, Jayapalan JJ, Abdul-Rahman PS, Omar SZ, Hashim OH: Enhanced expression of a $35 \mathrm{kDa}$ fragment of inter-alpha-trypsin inhibitor $\mathrm{H} 4$ in sera 
of healthy pregnant women and patients with hydatidiform mole. Biomarker Res 2013, 1:19.

44. Piñeiro $M$, Andrés $M$, Iturralde $M$, Carmona $S$, Hirvonen J, Pyörälä $S$, Heegaard PM, Tjørnehøj K, Lampreave F, Piñeiro A, Alava MA: ITIH4 (inter-alpha-trypsin inhibitor heavy chain 4) is a new acute-phase protein isolated from cattle during experimental infection. Infect Immun 2004, 72:3777-3782.

45. Wang F, Yang HJ, He HB, Wang CF, Gao YD, Zhong JF, Wang XH, Zeng YJ: Study on the hemolysin phenotype and the genotype distribution of Staphloccocus aureus caused bovine mastitis in Shandong dairy farms. Intern J Appl Res Vet Med 2011, 9:416-421.

46. Hou QL, Huang JM, Ju ZH, Li QL, Li LM, Wang CF, Sun T, Wang LL, Hou MH, Hang SQ, Zhong JF: Identification of splice variants, targeted microRNAs and functional SNPs of the BOLA-DQA2 gene in dairy cattle. DNA Cell Biol 2012, 31:739-744.

47. Guo F, Yang B, Ju ZH, Wang XG, Qi C, Zhang Y, Wang CF, Liu HD, Feng MY, Chen $Y, X u$ YX, Zhong JF, Huang JM: Alternative splicing, promoter methylation, and functional SNPs of sperm flagella 2 gene in testis and mature spermatozoa of Holstein bulls. Reproduction 2014, 147:241-252.

48. Bionaz M, Periasamy K, Rodriguez-Zas SL, Hurley WL, Loor JJ: A novel dynamic impact approach (DIA) for functional analysis of time-course omics studies: validation using the bovine mammary transcriptome. PLoS One 2012, 7:e32455.

doi:10.1186/1471-2164-15-839

Cite this article as: Huang et al:: iTRAQ-proteomics and bioinformatics analyses of mammary tissue from cows with clinical mastitis due to natural infection with Staphylococci aureus. BMC Genomics 2014 15:839.

\section{Submit your next manuscript to BioMed Central and take full advantage of:}

- Convenient online submission

- Thorough peer review

- No space constraints or color figure charges

- Immediate publication on acceptance

- Inclusion in PubMed, CAS, Scopus and Google Scholar

- Research which is freely available for redistribution 